\title{
Desain Sistem Edutaiment Berbasis Web di Sekolah Menengah Atas
}

\author{
Surya Ade Saputera ${ }^{1}$, Efni Yunita ${ }^{2}$ \\ ${ }^{1}$ Universitas Muhammadiyah Bengkulu \\ Jl. Bali. Bengkulu 38119 \\ adesurya2012@gmail.com ${ }^{1}$
}

\begin{abstract}
Web-based Information Systems in high schools will support the efficiency and effectiveness of work in providing material to students and facilitate communication nets between students and teachers both in terms of time and cost. The problems that will be examined in high school are lack of interest in student learning and less interesting ways of learning delivered by the teacher so that it will lead to less interest in learning students. The purpose of this writing is to study, analyze, and build edutaiment systems into a Web-based application program. The research method used is using the Incremental model. The final result of the research in high school is a Web-based application program that can increase students' interest in learning and also makes it easier to provide practice questions and material to students so students can learn while playing, and can also display information about important announcements in high school.
\end{abstract}

\section{Keywords: Website, Learning System}

\begin{abstract}
Abstrak-- Sistem Informasi Berbasis Web pada SMA akan menunjang efisiensi dan efektifitas kerja dalam memberikan materi kepada siswa dan mempermudah jalanya komunikasi antar siswa dan guru baik dari segi waktu maupun biaya.Adapun permasalahan yang akan di teliti pada SMA yaitu kurangnya minat belajar siswa dan cara pembelajaran yang kurang menarik yang disampaikan oleh guru sehingga akan menimbulkan kurang minat belajar siswa. Tujuan penulisan ini untuk mempelajari, menganalisis, dan membangun sistem edutaimentkedalam sebuah program aplikasi berbasis Web. Adapun metode penelitian yang di gunakan adalah menggunakan model Incremental. Hasil akhir dari penelitian pada SMA adalah program aplikasi berbasis Web yang dapat meningkatkan minat belajar siswa dan juga mempermudah untuk memberikan soal latihan maupun materi ke siswa supaya siswa bisa belajar sambil bermain, dan juga dapat menampilkan informasi tentang pengumuman penting yang ada di SMA.
\end{abstract}

\section{Kata Kunci : Website, Sistem pembelajaran}

\section{Latar Belakang.}

Pengembangan pengajaran berbasiskan teknologi informasi dalam dunia pendidikan sering disebut dengan e-Learning (electronic learning) yang dapat diartikan dengan proses belajar mengajar yang menggunakan komputer dan internet. Yang mana metode pembelajaran selama ini sangatlah membuat siswa/i atau pelajar merasa bosan dan jenuh karena dengan metode pembelajaran yang monoton dan tidak bervariasi. Akibatnya banyak anak sekolah yang merasa bosan belajar dan akhirnya bisa membuat anak tidak mau sekolah sehingga siswa/i atau pelajar ketinggalan pelajaran.

Edutainment adalah pendidikan yang menghibur atau menyenangkan. Pada dasarnya, edutainment berusaha untuk mengajarkan atau memfasilitasi interaksi sosial kepada para siswa dengan memasukkan berbagai pelajaran dalam bentuk hiburan yang sudah akrab di telinga mereka, seperti acara televisi, permainan yang ada di komputer atau video games, film, musik, website, perangkat multimedia, dan sebagainya. Di samping itu, edutainment juga bisa berupa pendidikan di alam bebas, yang mampu menghibur sekaligus belajar tentang kehidupan binatang dan habitatnya.[1]
Dalam proses belajar dan mengajar di Sekolah Menengah Atas (SMA) seringkali yang menjadi permasalahan yakni adanya kecenderungan perbedaan antara harapan dan tindakan, bahkan terlihat monoton, membosankan, dan bersifat kaku. Guru membicarakan realitas seolah-olah sesuatu yang tidak bergerak, statis,terpisah satu sama lain, dan dapat diramalkan. Atau, dia menguraikansebuahtopik yang sama sekali asing bagi pengalaman dan eksistensi para murid.Tugasnya adalah "mengisi" para murid dengan segala bahan yang dituturkan-bahan-bahan yang lepas dari realitas, terpisah dari totalitas yang melahirkan dan dapat memberinya arti.[2]

Oleh karena itu dalam upaya meningkatkan proses belajar dan mengajar siswa Sekolah Menengah Atas para siswa diperlukan sebuah sistem yang menggabungkan teknologi informasi dengan kurikulum yang ada saat ini untuk membuat proses belajar mengajar lebih menarik dan mudah bagi para siswa itu untuk menangkap dan mengembangkan kreativitas mereka. Dengan menciptakan dan menggunakan media media hiburan yang sangat cepat memberi pengaruh kepada siswa dalam belajar dengan harapan hasil pembelajaran yang lebih optimal. Pembelajaran tersebut menggunakan metode pembelajaran Edutainment, yakni 
kombinasi dari education dengan entertainment, untuk memberikan warna baru dalam proses pendidikan antara guru dan siswa Sekolah Menengah Atas.

Berdasarkan latar belakang permasalahan yang ada maka masalah tersebut dapat dirumuskan yaitu “ Bagaimana mendesain sistem edutainment berbasiskan web di Sekolah Menengah Atas.

\section{Landasan Teori}

A. Pengertian Desain dan Sistem

Desain merupakan sekumpulan alat dan konsep untuk membantu persiapan produk-produk dan jasa-jasa yang berhasil [3]. Sistem adalah suatu jaringan kerja dari prosedur-prosedur yang saling berhubungan, berkumpul bersama-sama untuk melakukan suatu kegiatan atau untuk menyelesaikan suatu sasaran yang tertentu" [4]. Dengan kata lain, sistem adalah suatu kesatuan usaha yang terdiri dari bagian-bagian yang berkaitan satu sama lain yang berusaha mencapai satu tujuan dalam satu lingkungan kompleks. Dari pengertian tersebut mencerminkan adanya beberapa bagian dan hubungan antara bagian, ini menunjukan kompleksitas dari sistem yang meliputi kerja sama antara interpenden satu sama lain. Selain itu dapat dilihat bahwa sistem berusaha mencapai satu tujuan.

\section{B. Pengertian Edutainment}

Edutainment berasal dari 2 kata yaitu education yang berarti pendidikan dan entertainment yang berati hiburan. Dari segi bahasa edutainment memiliki arti pendidikan yang menyenangkan, sedangkan dari segi terminologi edutainment bisa diartikan sebagai bentuk hiburan yang dirancang dalam bentuk pendidikan. Jadi, edutainment bisa didefinisikan sebagai proses pembelajaran yang didesain dengan memadukan antara muatan pendidikan dan hiburan secara harmonis, sehingga aktivitas pembelajaran berlangsung dengan menyenangkan [1]

\section{AplikasiEdutainment}

Pembelajaran berbasis edutainment didesain dengan aplikasi hiburan di dalam Proses Belajar Mengajar (PBM) baik di dalam kelas (indoorlearning) maupun di luar kelas (outdoor learning), baik hiburan dengan nyayian, brain gym, music, outbond, atau pun menggunakan metode-metode pembelajaran yang menyenangkan, seperti, diskusi, cerdas cermat, dan lainlain.

Tujuan hiburan dalam pelaksanaan pembelajaran adalah agar pembelajaran terasa menyenangkan, sehingga peserta didik merasa "nyaman", "aman", "enjoy", "santai", dan kelas tidak terkesan tegang, menakutkan, tidak nyaman, terancam, tertekan, dan lain-lain.Aplikasi Edutainmentbertujuan sebagai aplikasi pembelajaran dengan konsep yang menyenangkan. Namun demikian, aplikasi

Banyak para guru atau pun dosen salah dalam memaknai sebuah PBM. Kata mereka, PBM yang sukses adalah dimana di dalam kelas para peserta didik dapat duduk tenang, mendengarkan, tidak ramai sendiri, tidak berisik, tidak banyak gerak kesana kemari, dan guru bisa mengajarkan dengan keadaan hening.

Pembelajaran model di atas, mengandung dua dampak, baik dampak positif maupun negatif. Dampak positifnya, bagi anak-anak dengan tipe belajar auditorial dan visual, keadaan tenang di kelas, baik karena takut sama gurunya atau karena kewibawaan gurunya, akan membantu mereka dapat belajar dengan tenang, tapi bagi anak-anak yang memiliki tipe belajar kinestetik, pembelajaran model seperti ini akan memenjarakan kreatifitas dia.Dampak negatifnya, pembelajaran seperti ini akan memenjarakan kreatifitas semua peserta didik, seperti takut bertanya, gerak sedikit dimarahi, takut berbeda dengan pendapat guru, anak-anak merasa tertekan di dalam kelas, dan lain sebagainya.

\section{Mengenal Model Belajar Peserta Didi}

Agar guru sukses dalam pelaksanaan pembelajaran berbasis edutainment, seorang guru harus mengenali model belajar setiap peserta didik. Ada teori model belajar yang dinamakan V-A-K dan S-A-V-I.

1. V-A-K.

Merupakan singkatan dari Visual, Auditorial, Kinestetik. Pelajar tipe visual menyerap pengetahuan melalui apa yang mereka lihat, pelajar auditorial melakukannya melalui apa yang mereka dengar, dan pelajar kinestetik belajar lewat gerak dan sentuhan [4]

2. S-A-V-I.

Merupakan metode yang dikembangkan oleh Dave Meier. ${ }^{5}$ yaitu:

a. Somatic : Learning by moving and doing

b. Auditory : Learning by talking and hearing

c. Visual : Learning by observing and picturing

d. Intellectual : Learning by problem solving and reflecting

Tipe pelajar somatic, dia belajar dengan bergerak dan berbuat. Tipe ini sama dengan tipe Kinestetik, mereka lebih enak belajar dengan praktik secara langsung. Tipe pelajar auditory, dia belajar dengan cara berbicara dan mendengarkan. Pelajar auditory lebih banyak menggunakan telinga sebagai alat untuk menyerap informasi. Tipe pelajar visual, dia belajar observasi dan melihat gambar. Pelajar visual lebih banyak menggunakan mata sebagai alat untuk menyerap informasi. Tipe pelajar intellectual, dia belajar dengan cara memecahkan masalah (problem solving) dan refleksi.

\section{E. UML(Unified Modeling Language)}

UML adalah Bahasa standar untuk membuat rancangan software. UML biasanya digunakan untuk menggambarkan dan membangun, dokumen artifak dari software-intensive system [6]. UML (unified modeling language) sesuai dengan kata-kata terakhir dari kepanjanganya, UML merupakan salah satu bentuk language atau bahasa. Menurut pencetusnya, UML didefinisikan sebagai bahasa visual untuk menjelaskan, memberikan spesifikasi, merancang, membuat model dan mendokumentasikan aspek-aspek dari sebuah sistem.

Karena merupakan bahasa visual, UML lebih mengedepankan penggunaan diagram untuk 
menggambarkan aspek darin sistem yang sedang dimodelkan. Bahasa visual lebih ke mental model pikiran kita, sehingga permodelan menggunakan bahasa visual lebih mudah dan lebih cepat dipahami dibandingkan apabila dituliskan dalam sebuah bahasa pemrograman.

Unified Modeling Language (UML)adalah sebuah "bahasa" yang telah menjadi standar dalam industri untuk visualisasi, merancang dan mendokumentasikan sistem piranti lunak, UML menawarkan sebuah standar untuk merancang model sebuah sistem.

\section{F. Use Case Diagram}

Use case diagram merupakan sebuah teknik yang digunakan dalam pengembangan sebuah atau sistem informasi untuk menangkap kebutuhan fungsional dari sistem yang bersangkutan.Use case menggambarkan external view dari sistem yang akan kita buat modelnya [7]. Use case diagram menjelaskan interaksi yang terjadi antara " aktor" dan " inisiator" dari interaksi sistem itu sendiri dengan sistem yang ada, sebuah use case direpresentasikan dengan urutan langkah yang sederhana.

Fokus dari sebuah use case adalah bagaimana mencapai sebuah tujuan atau goal. Setiap use case merupakan rangkaian seri yang lengkap dari event kejadian jika dilihat dari sudut pandang actor. Actor merupakan sesuatu atau seseorang yang ada di luar sistem dan ikut berperan serta dalam aktifitas sistem. Aktor bisa berperan end user, perangkat hardware, bahkan sistem yang lain.

Dalam pengembangan software dibutuhkan banyak use case mendefinisikan sebuah scope dari sebuah sistem. Derajat formalitas dari sebuah sistem yang dikembangkan menentukan level detail yang dibutuhkan dari sebuah use case.Use case sebaiknya jangan dicampur adukan dengan fitur dari sistem, sebuah fitur mungkin terealisasi dengan satu atau lebih use case.

Tabel 1 Simbol Use Case

\begin{tabular}{|l|l|l|}
\hline No. & \multicolumn{1}{|c|}{ Simbol } & \multicolumn{1}{|c|}{ Keterangan } \\
\hline 1. & Aktor & $\begin{array}{l}\text { Merupakan kesatuan } \\
\text { eksternal yang berinteraksi } \\
\text { dengan system. }\end{array}$ \\
\hline 2. & $\begin{array}{l}\text { Use Case } \\
\text { Rangkaian/uraian } \\
\text { sekelompok yang saling } \\
\text { terkait dan membentuk } \\
\text { sistem. }\end{array}$ \\
\hline 3. & $\begin{array}{l}\text { Gengerelation } \\
\text { khusus atau interaksi dalam } \\
\text { objek. }\end{array}$ \\
\hline
\end{tabular}

\section{G. Class Diagram}

Class diagram adalah diagram yang digunakan untuk menampilkan beberapa kelas serta paket-paket yang ada dalam sistem atau perangkat lunak yang sedang kita kembangkan. Kelas sebagai suatu set objek yang memiliki atribut dan perilaku yang sama, kelaskadang disebut kelas objek [8]

\section{Nama Kelas \\ Atribut \\ Operasi \\ Gambar 1 DesainClass Diagram}

\section{H. Activity Diagram}

Activity diagram bersifat dinamis, diagram aktifitas ini adalah tipe khusus dari diagram state yang memperlihatkan aliran dari suatu aktifitas ke aktifitas lainnya dalam suatu sistem. Diagram ini terutama penting dalam permodelan fungsi-fungsi dalam sistem dan memberi tekenan pada aliran kendali antar objek. Activity sendiri artinya perilaku yag dilakukan suatu objek pada state [9].

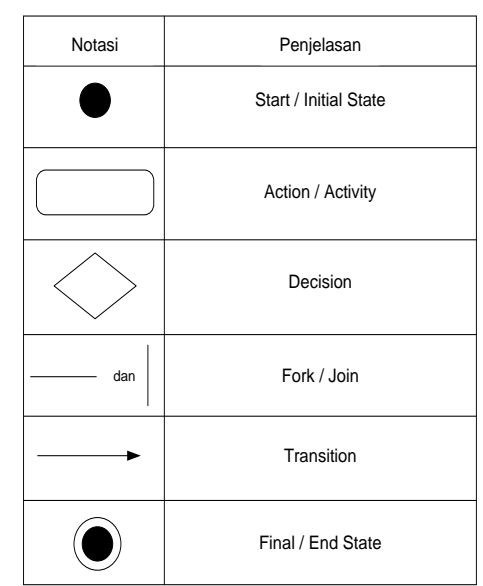

Gambar 2 Notasi Activity Diagram

\section{Metode Penelitian}

A. Metode Pengembangan Sistem

Model incremental (Incremental waterfall model) merupakan perbaikan dari model waterfall dan sebagai standar pendekatan top-down. Incremental model dipilih karena metode ini dapat meminalisir ketidak sesuaian dalam pengembangan perangkat lunak [10]. Ide dasar dari model ini adalah membangun software secara meningkat (increment) berdasarkan kemampuan fungsional. Model incremental ini diaplikasikan pada sistem pakar dengan penambahan rules.

Model incremental merupakan model continous rapid prototype dengan durasi yang diperpanjang hingga akhir proses pengembangan. Pada model prototipe biasa, prototipe hanya dibuat pada tahap awal untuk mendapatkan kebutuhan user

\section{B. Analisis dan Perancangan Sistem}

Tahap analisis dan perancangan sistem untuk merancang sistem edutainment ini menggunakan prototyping sebagai metode pengembangan sistem. Prototyping adalah implementasi bagian dari produk software yang secara tipikal fungsinya dibatasi, realibitasan rendah, tampilan miskin, dan kurang ketegasan.Prototypingmerupakan metode pengembangan perangat lunak, yang berupa model fisik 
kerja sistem dan berfungsi sebagai versi awal dari system [11].

Prototyping sendiri dimulai dengan requirement gatherings yaitu perancang dan konsumen bertemu dan mendiskusikan sistem seperti apa yang akan dibangun. Serta menentukan tujuan umum dari sistem yang akan dibangun, mengidentifikasi kebutuhan sistem sehingga menghasilkan suatu "quick design" yang akan membentuk suatu prototype.

\section{Rancang Bangun Prototyping}

Pada tahap ini dibangun prototyping dengan membuat perancangan sementara yang berfokus pada penyajian sekolah.

Langkah pertama dalam membangun prototyping sistem adalah mendeskripsikan pemakai/user yang akan menggunakan sistem ini.

Sistem yang dikembangkan ini adalah aplikasi yang berbasiskan web. Dalam sistem ini terdapat 3 pengguna yang saling berinteraksi di dalam sistem, yaitu

1. Admin

2. Guru

3. Siswa

Admin mengolah proses login untuk user lainnya seperti pemberian user id dan password. Admin juga bertindak sebagai pengatur penjadwalan mata pelajaran, dan pembagian kelas belajar bagi guru dan siswa.

Guru yang mengajar di masing-masing mata pelajaran mampu mengakses data siswa dan kelas yang di pilih, juga menyampaikan pelajaran dalam bentuk video, tutorial, makalah.Selain itu guru juga mengupload materi ke dalam sistem dan membuat ujian secara online, serta mengupload nilai ujian siswa.Guru juga bisa melakukan virtual diskusi dengan chatting di kelas virtual dan forum.

Siswa bisa mengakses ke dalam sistem dengan menggunakan user id dan password yang telah dberikan oleh admin. Siswa dapat men-download materi pelajaran yang telah di-upload oleh guru serta melihat kelas belajar. Siswa juga dapat mengikuti ujian online yang diberikan oleh guru dan melihat hasil ujian tersebut.

Berdasarkan gambaran hubungan antar pengguna di atas dapat dibentuk suatu lingkungan sistem edutainment yang memungkinkan terjadinya hubungan tersebut. Hubungan tersebut akan dibawa melalui media web di atas teknologi internet. Pada tahap ini adalah tahapan pengumpulan semua kebutuhan sistem yang akan dibangun membutuhkan perancangan sistem (desain) dalam sistem itu sendiri.

Selanjutnya membuat alur sistem yang akan digunakan. Penggambaran sistem ini menggunakan UML ( Unified Model Language) yang terdiri dari 3 diagram yaitu use case diagram, class diagram, dan activity diagram. Adapun tahapan perancangan sistem yang akan di bangun adalah sebagai berikut :

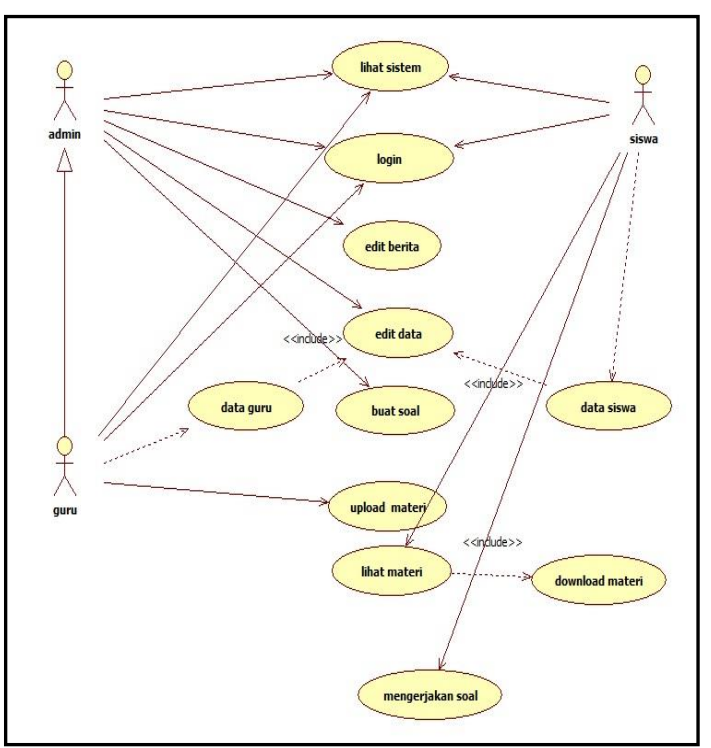

Gambar 3 Use Case Diagram

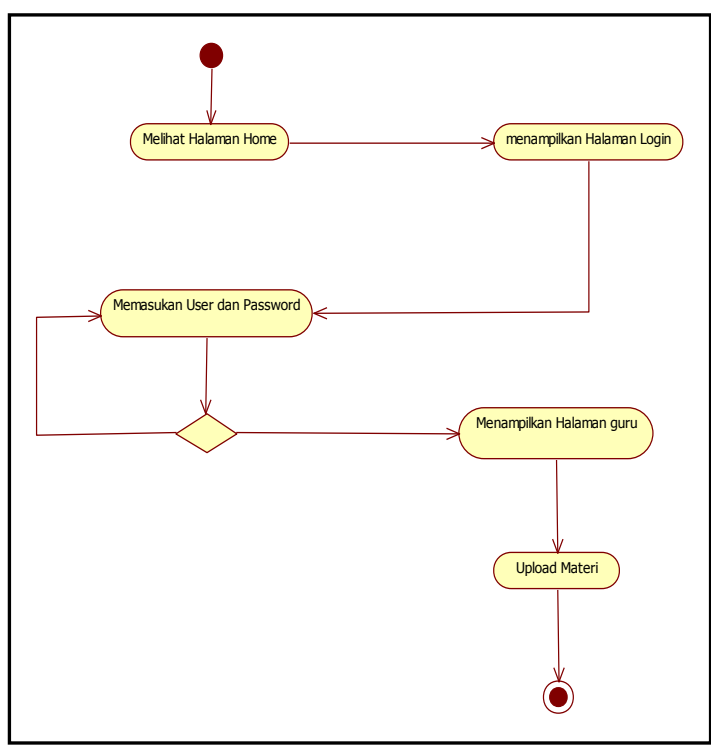

Gambar 4 Activity Diagram Admin

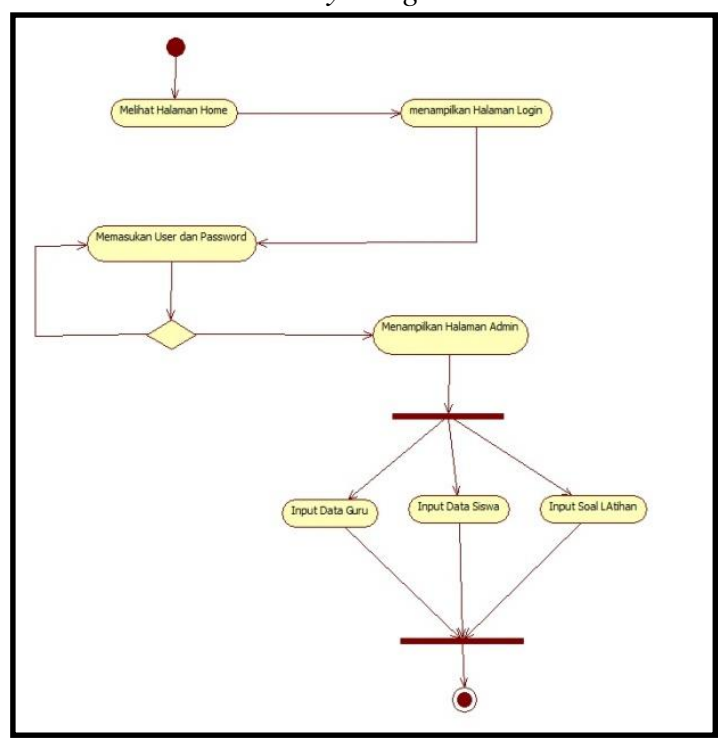

Gambar 5 Activity Diagram Guru 


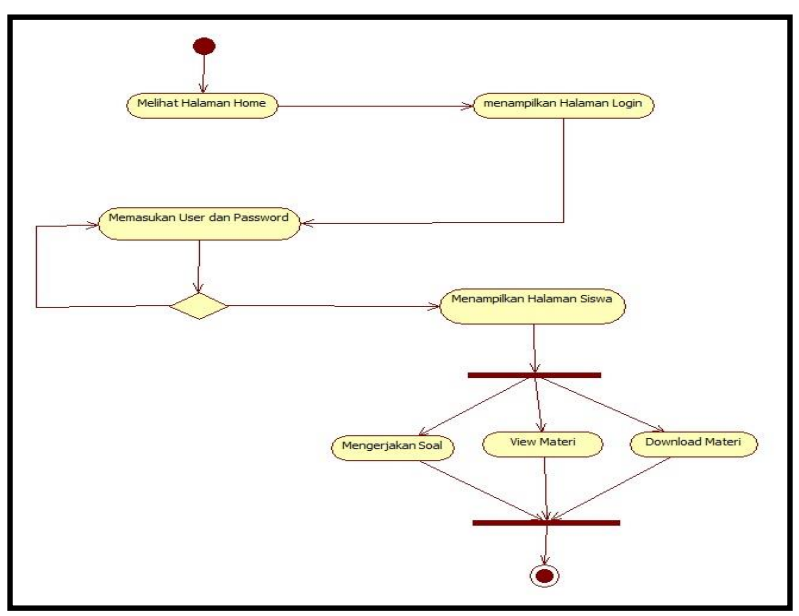

Gambar 5 Activity Diagram Siswa

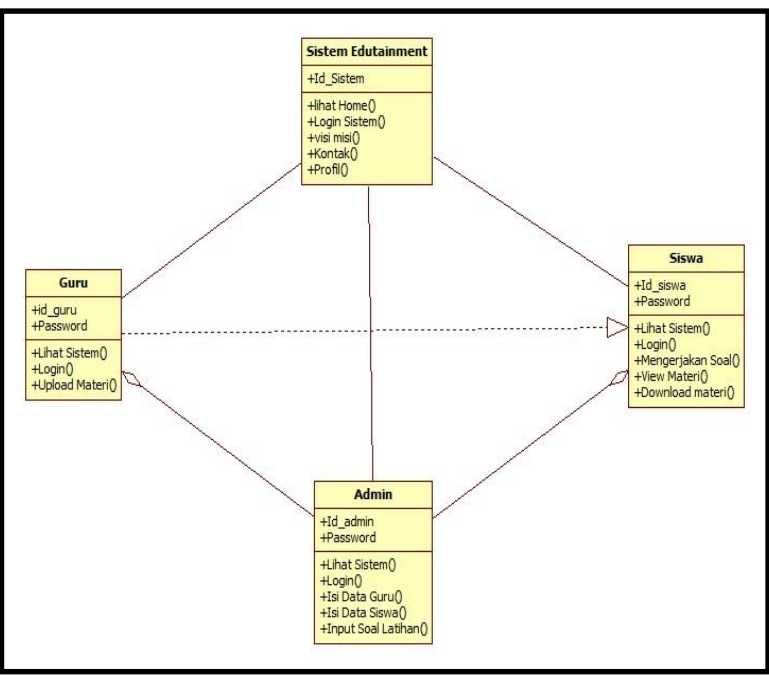

Gambar 4Class DiagramSistem Edutainment

Tabel 2 Rancangan Tabel User

\begin{tabular}{|l|l|l|l|l|}
\hline No & \multicolumn{1}{|c|}{ Field } & \multicolumn{1}{|c|}{ Type } & Size & Keterangan \\
\hline 1. & Id & Integer & 11 & Id User \\
2. & User & Varchar & 50 & Kode User \\
3. & Password & Varchar & 50 & Password \\
4. & Status & Varchar & 20 & User \\
5. & Aktif & Varchar & 6 & Status User \\
& & & & Masa Aktif \\
& & & & User \\
\hline
\end{tabular}

Tabel 3 Rancangan Tabel Guru

\begin{tabular}{|l|l|l|l|l|}
\hline No & Field & Type & Size & Keterangan \\
\hline 1. & Nip & Varchar & 15 & Nip Guru \\
2. & Nama & Varchar & 30 & Nama Guru \\
3. & Jk & Varchar & 12 & Jenis Kelamin \\
4. & TTL & Date/time & $00-$ & Guru \\
5. & Kelas & Varchar & $00-$ & Tempat \\
6. & Photo & Text & 0000 & Tanggal Lahir \\
7. & Alamat & Varchar & 5 & Guru \\
8. & Kota & Varchar & 200 & Kelas \\
9. & Prov & Varchar & 50 & Photo Profil \\
10. & Kp & Varchar & 50 & Alamat Guru \\
11. & Tlp & Varchar & 8 & Kota asal \\
& & & 14 & Provinsi \\
\hline
\end{tabular}

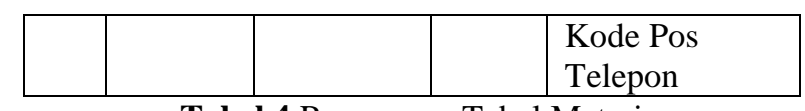

Tabel 4 Rancangan Tabel Materi

\begin{tabular}{|l|l|l|l|l|}
\hline No & \multicolumn{1}{|c|}{ Field } & Type & Size & \multicolumn{1}{|c|}{ Keterangan } \\
\hline 1. & Id & Varchar & 10 & Kode Materi \\
2. & Judul & Varchar & 20 & Judul Materi \\
3. & Tgalpost & Varchar & 10 & Tanggal Posting \\
4. & Dokumen & Varchar & 15 & Materi \\
5. & Pelajaran & Varchar & 15 & Dokumen Materi \\
6. & Terbit & Varchar & 15 & Jenis Pelajaran \\
& & & & Keterangan Terbit \\
\hline
\end{tabular}

Tabel 5 Rancangan Tabel Berita

\begin{tabular}{|l|l|l|l|l|}
\hline No & \multicolumn{1}{|c|}{ Field } & Type & Size & \multicolumn{1}{|c|}{ Keterangan } \\
\hline 1. & Id & Integer & 11 & Kode Berita \\
2. & Judul & Text & & Judul Berita \\
3. & Isi & Text & & Isi Berita \\
4. & Gambar & Text & & Gambar Berita \\
5. & Tglpost & Date & & Tanggal Terbit \\
6. & Terbit & Char & 2 & Keterangan Terbit \\
\hline
\end{tabular}

\section{Hasil dan Pembahasan}

Sistem edutainment berbasis web pada SMA Negeri 1 Curup mempuyai cakupan yang sangat luas karena sistem ini berbasis kanweb. Terdapat 3 pengguna dalam sistem ini yaitu administrator, guru dan siswa yang dapat menggunakan sistem ini dengan masingmasing fungsi yang berbeda :

\section{Administrator}

Di dalam sistem ini tugas seorang administrator adalah menambahkan data dan mengolah data yang berhubungan dengan sistem ini, seperti memasukan data guru, data siswa, memasukan berita terbaru, pengumuman sekolah, dan soal latihan. Untuk mengolah data tersebut administrator harus melakukan login pada halamanhome yang merupakan halaman awal dari sistem ini.

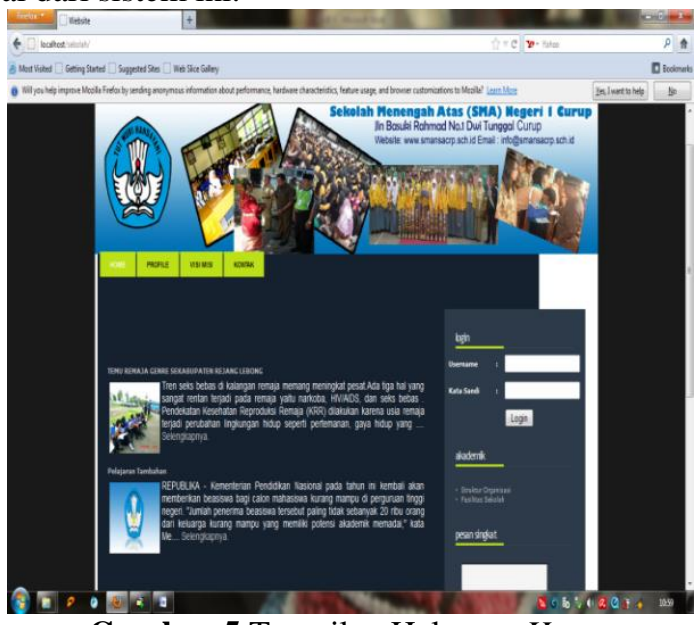

Gambar 5 Tampilan Halaman Home

Administrator harus mengisi user id dan password yang dimiliki pada kotak/ field yang tersedia, jika terjadi

181 | http://www.jurnal.umb.ac.id/index.php/JSAI 
kesalahan maka sistem akan meminta pengulangan pengisian kepada administrator. Pengisian user iddan password juga harus dilakukan oleh setiap user yakni guru dan siswa.Setelah administrator melakukan login dengan benar maka administrator akan masuk ke halaman administrator yang tersediasehingga administrator bisa memasukan data keperluan seperti data guru, siswa dan lainnya

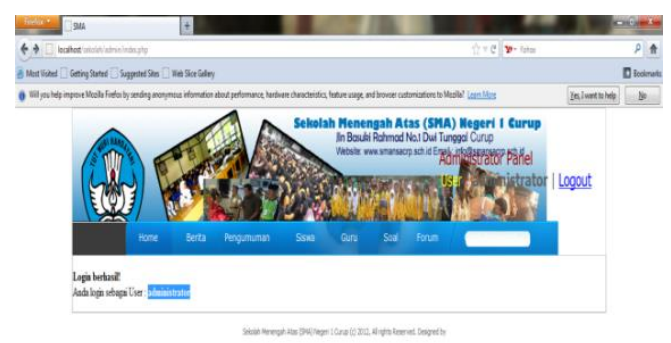

Ge. o Gambar 6. Tampilan Halaman Admin

Pada halaman tampilan halaman awal administrator terdapat beberapa menu yang bisa administrator olah seperti menu home, memungkinkan administrator kembali ke halaman awal administrator. Selanjutnya menu berita yang memungkinkan administrator untuk memasukan berita seputar dunia pendidikan.

\section{Guru}

Guru sebagaiuser yang menambahkan materi dan nilai untuk siswa. Sama seperti administrator, guru harus memasukan user id dan password untuk masuk ke dalam sistem. Setelah berhasil melakukan proses login, terdapat beberapa menu pilihan yang bisa diakses guru seperti biodata untuk melihat biodata guru tersebut, input nilai untuk menginput nilai mahasiswa, upload materi untuk melakukan upload materi belajar yang nantinya akan diakses oleh siswa.Link biodata akan menampilkan biodata guru yang datanya telah diisi oleh administrator. Link biodata ini juga terdapat di halaman siswa

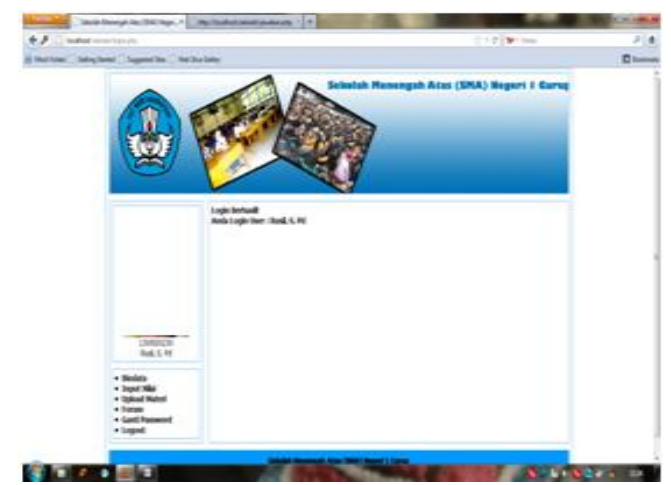

Gambar 7Tampilan Halaman Biodata Guru
Link/button selanjutnya ialah input materi yang berfungsi bagi guru untuk menambahkan materi pembelajaran dengan cara mengklik mata pelajaran dan guru bisa menambahkan pelajaran sesuai mata pelajaran guru mengajar. Guru juga dapat menampilkan materi dalam bentuk multi media jika memungkinkan.

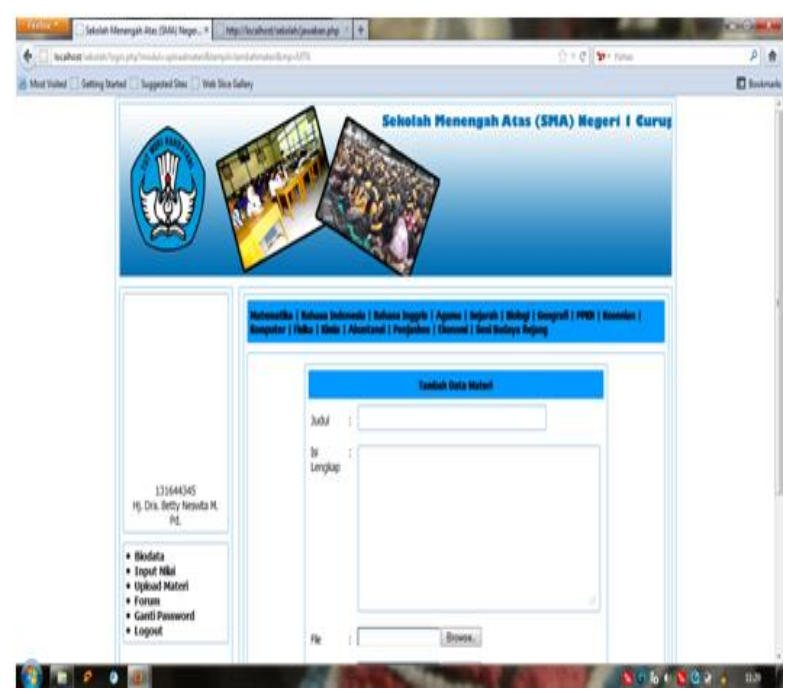

Gambar 8Tampilan Halaman Input Materi

3. Siswa

Sama seperti administrator dan guru, siswa dapat mengakses sistem apabila telah melakukan login dengan mengisi user id danpassword dengan benar. User id dan password yang dimiliki oleh siswa sama dengan guru yaitu berdasarkan nomor identitas siswa yang telah diisi oleh administrator sebelumnya. Siswa juga bisa melihat biodata yang telah administrator isi di halaman administrator sebelumnya.

Siswa dapat mengerjakan soal yang telah dibuat oleh administrator yang telah mendapatkan materi pelajaran yang sebelumnya diberikan oleh guru. Dengan memilih kategori soal yang terdapat di halaman siswa , siswa dapat mengerjakan soal yang nantinya nilai hasil akan langsung tampil.

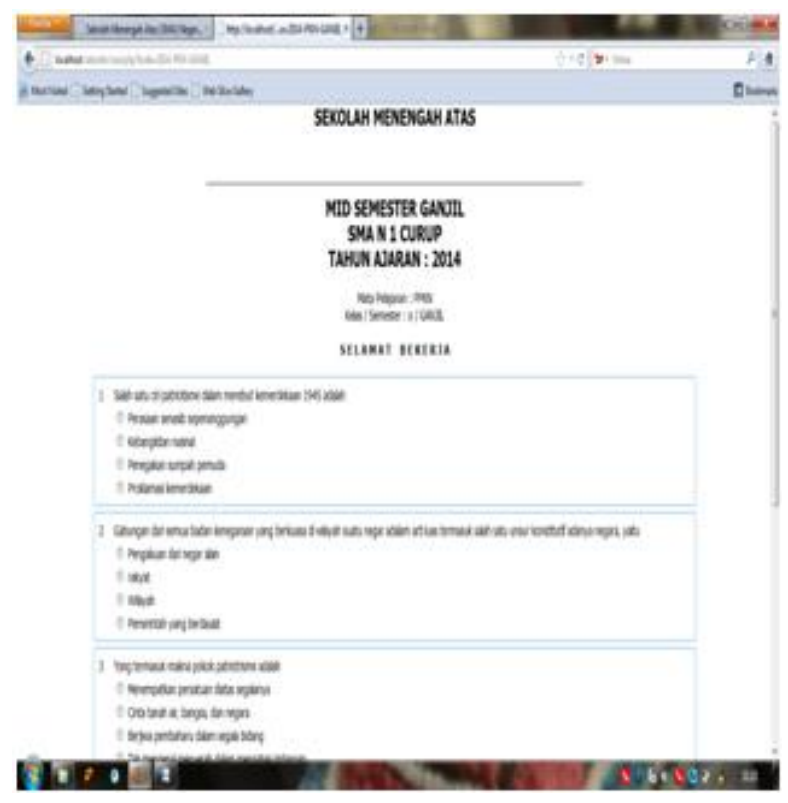

182 | http://www.jurnal.umb.ac.id/index.php/JSAI 
Gambar 9Tampilan Halaman Latihan Soal

\section{Kecepatan Koneksi}

Dari segi kecepatan proses, sistem ini masih memiliki kekurangan yang mana sistem ini belum terkoneksi dengan internet secara online sehingga tingkat kecepatan koneksi belum bisa ditentukan

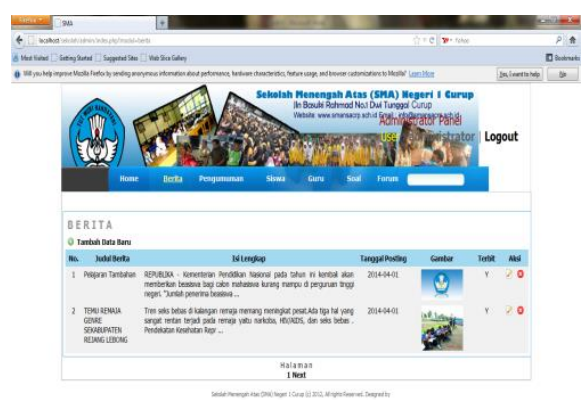

Gambar 10 Tampilan Halaman Input Berita Menu berita yang memungkinkan administrator untuk memasukan berita seputar dunia pendidikan

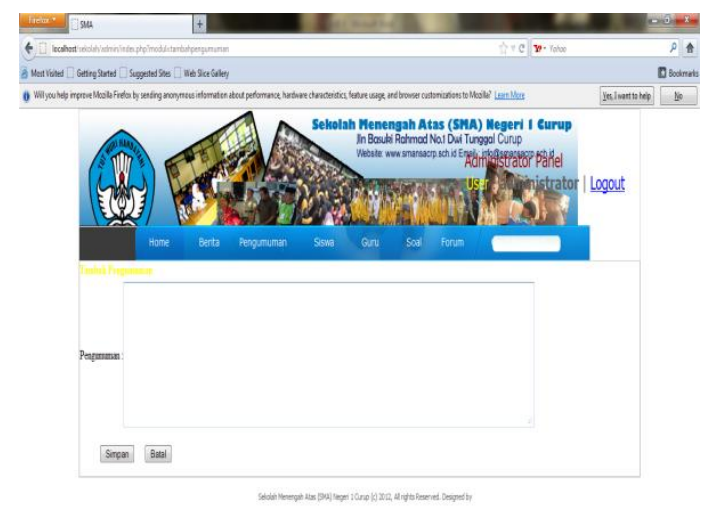

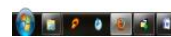

Gambar 11 Tampilan Halaman Input Pengumuman Memasukan pengumuman seputar kegiatan sekolah dengan mengklik button pengumuman yang berada disebelah button berita.

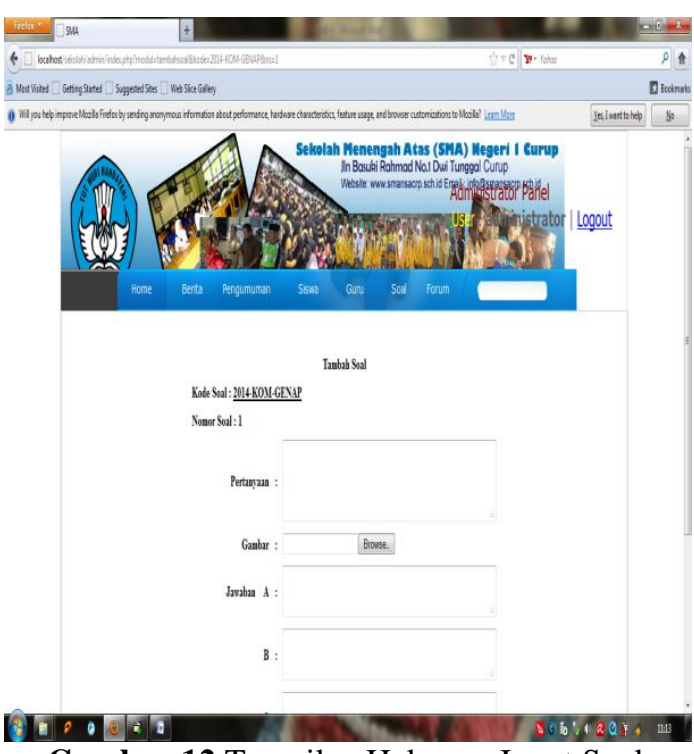

Gambar 12 Tampilan Halaman Input Soal Membuat soal latihan dan ujian dengan materi yang telah diberikan oleh guru mata pelajaran.

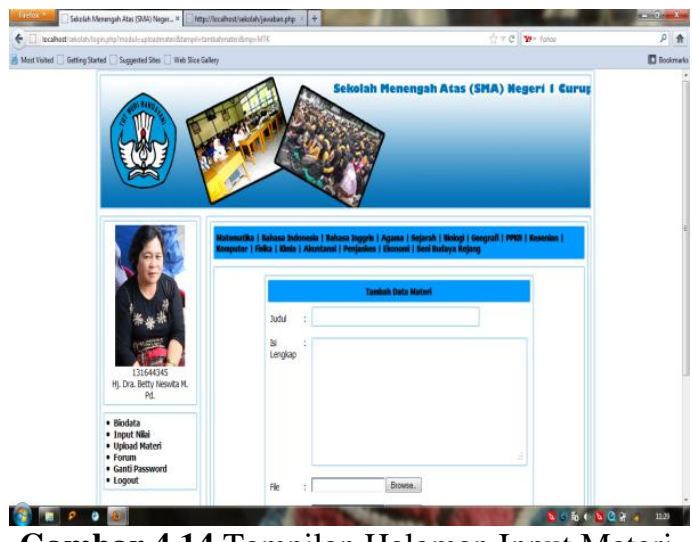

Gambar 4.14 Tampilan Halaman Input Materi

Berfungsi bagi guru untuk menambahkan materi pembelajaran dengan cara mengklik mata pelajaran dan guru bisa menambahkan pelajaran sesuai mata pelajaran guru mengajar. Guru juga dapat menampilkan materi dalam bentuk multi media jika memungkinkan.

\section{Kesimpulan dan Saran}

Berdasarkan hasil pembahasan dapat ditarik kesimpulan dengan model pembelajaran dengan desain sistem yang interaktif, menggunakan visual dan warna ketertarikan siswa dalam belajar bisa lebih tinggi. Sistem ini dirancang berbasiskan web agar memudahkan pengguna dan lebih memanfaatkan jaringan sistem yang ada di SMA.

Dalam pengembangan sistem edutainment ke depan diharapkan agar tampilan dari sistem edutainment dibuat lebih menarik dan lebih baik dari sistem edutainment yang dirancang sekarang. Perlu di lakukan proses evaluasi untuk mengetahui tingkat penerimaan user terhadap sistem Edutaiment menggunakan Pendekatan TAM (Technology Acceptance Model). 


\section{Referensi}

[1] Hamid, M.S. (2011). Metode Edutainment. Yogyakarta: Diva Press

[2] Freire, Paulo. 2013. Pendidikan Kaum Tertindas(Pedagody of The Oppressed). Jakarta: LP3ES.

[3] Kotler, Philip. 2002. Manajemen Pemasaran. Jakarta : Salemba empat

[4] Jogiyanto, H.M., 2005, Analisa dan Desain Sistem Informasi: Pendekatan Terstruktur Teori dan Praktik Aplikasi Bisnis, ANDI, Yogyakarta

[4] Huda, Miftahul. 2013. Model-model PengajarandanPembelajaran. Yogyakarta: PustakaPelajar.

[5] Tarigan, Henry Guntur. 2009. PengkajianPragmatik. Bandung: Angkasa

[6] Booch, G., James Rumbaugh, Ivar Jacobson. The Unified Modeling Language User Guide,Addison Wesley, New York, 2005.

[7] Widodo, Prabowo Pudjo. 2011. Menggunakan UML. Bandung: Informatika

[8] Witten, Jeffery L, et all.2004.Metode Disain \& Analysis Sistem (Terjemahan). Yogyakarta: Andi Offset.

[9] Haviluddin. (2011). Memahami Penggunaan UML (Unified Modelling Language). Jurnal Informatika Mulawarman. Retrieved from http://ejournals.unmul.ac.id/index.php/JIM/article /view/16.

[10] R. S. Pressman, "The Incremental Model," in Software Engineering, A Practitioner's Approach, New York, McGraw-Hill Series in Computer Science, p. 36.

[11] Ogedebe, P.M.,\& Jacob, B.P. , 2012, Software Prototyping: A Strategy to Use When User Lacks Data Processing Experience. ARPN Journal of Systems and Software. VOL. 2, NO.6 , 2012, http://scientificjournals.org/journalofsystemsandsoftware/archive /vol2no6/vol2no6_4.pdf 